\title{
BMJ Open Effect of smoke-free legislation on respiratory health services use in children with asthma: a population- based open cohort study in Ontario, Canada
}

\author{
Teresa To (D) , ${ }^{1,2}$ Ivy Fong, ${ }^{1}$ Jingqin Zhu, ${ }^{1,3}$ Rachel McGihon, ${ }^{1}$ Kimball Zhang, \\ Emilie Terebessy ${ }^{1}$
}

To cite: To T, Fong I, Zhu J, et al. Effect of smoke-free legislation on respiratory health services use in children with asthma: a populationbased open cohort study in Ontario, Canada. BMJ Open 2021;11:e048137. doi:10.1136/ bmjopen-2020-048137

- Prepublication history and additional supplemental material for this paper are available online. To view these files, please visit the journal online. (http://dx.doi.org/10.1136/ bmjopen-2020-048137).

Received 21 December 2020 Accepted 23 July 2021

Check for updates

(c) Author(s) (or their employer(s)) 2021. Re-use permitted under CC BY-NC. No commercial re-use. See rights and permissions. Published by BMJ.

${ }^{1}$ Child Health Evaluative Sciences, The Hospital for Sick Children, Toronto, Ontario, Canada

${ }^{2}$ Dalla Lana School of Public Health, University of Toronto, Toronto, Ontario, Canada

${ }^{3}$ Institute for Clinical Evaluative Sciences, Toronto, Ontario, Canada

Correspondence to

Dr Teresa To;

teresa.to@sickkids.ca

\section{ABSTRACT}

Objective This study will add to existing literature by examining the impact of smoke-free legislation in outdoor areas among children with asthma. We aimed to examine the effect of the 2015 Smoke-Free Ontario Act (SFOA) amendment, which prohibited smoking on patios, playgrounds and sports fields, on health services use (HSU) rates in children with asthma.

Methods We conducted a population-based open cohort study using health administrative data from the province of Ontario, Canada. Each year, all Ontario residents aged 0-18 years with physician diagnosed asthma were included in the study. Annual rates of HSU (emergency department (ED) visits, hospitalisations and physician office visits) for asthma and asthma-related conditions (eg, bronchitis, allergic rhinitis, influenza and pneumonia) were calculated. Interrupted time-series analysis, accounting for seasonality, was used to estimate changes in HSU following the 2015 SF0A.

Results The study population ranged from 618957 individuals in 2010 to 498812 in 2018 . An estimated average increase in ED visits for asthma in infants aged $0-1$ years of 0.42 per 100 individuals $(95 \% \mathrm{Cl}: 0.09$ to 0.75 ) and a $57 \%$ relative increase corresponding to the 2015 SFOA was observed. A significant decrease in ED visits for asthma-related conditions of 0.19 per 100 individuals ( $95 \% \mathrm{Cl}:-0.37$ to -0.01$)$ and a $22 \%$ relative decrease corresponding to the 2015 SFOA was observed. Conclusion Based on the observed positive effect of restricting smoking on patios, playgrounds and sports fields on respiratory morbidity in children with asthma, other jurisdictions globally should consider implementing similar smoke-free policies.

\section{INTRODUCTION}

Exposure to environmental tobacco smoke increases the severity of asthma and is an important preventable exposure predisposing asthma exacerbations in children. ${ }^{2}$ Secondhand smoke exposure can effectively be reduced by creating comprehensive

\section{Strenghts and limitations of this study}

- Using 9 years of health administrative data from Ontario, Canada, our study is one of the largest population-based cohort studies to examine the impact of smoke-free legislation in children with asthma.

- We used interrupted time-series analysis, accounting for seasonality, to estimate changes in health services use following the 2015 amendment to the Smoke-Free Ontario Act, which prohibited smoking on patios, playgrounds and sports fields.

- This study builds on existing literature in this research area and will help to demonstrate the realworld impact of smoke-free legislation on health outcomes among children and youth with asthma.

- Limitations of this study included lack of clinically relevant risk factors, accounting for reduction in air pollution and smoking due to other campaigns, a control province and inferring individual-level impact of the intervention.

smoke-free public environments enacted through legislation. $^{3-5}$

While the research on the effects of legislation for smoke-free public environments on adults is well informed, studies on the effects for children are limited and varying. There was no association, immediate nor gradual, between smoke-free legislation and hospital admissions for asthma among children in Canada and Spain. ${ }^{6}$ In contrast, observational studies in Scotland, England and the USA have found associated reductions in paediatric emergency department (ED) visits for asthma after the implementation of smoke-free legislation. ${ }^{8-10}$ Additionally, in a recent meta-analysis which included some of the studies described previously, smoke-free legislation was found to result in an immediate $9.8 \%$ reduction of asthma exacerbations 
requiring hospital attendance and a gradual reduction of $5.9 \%$ per year. ${ }^{11} \mathrm{~A}$ slightly earlier meta-analysis echoed similar inconsistencies in findings on the effects of legislative smoking bans on respiratory and perinatal health. ${ }^{12}$

In 2015, the Smoke-Free Ontario Act (SFOA) was amended to prohibit smoking on patios, playgrounds and sports fields. ${ }^{13}$ The 2015 SFOA amendment was intended to target and protect children from the harmful effects of smoke exposure by banning smoking in environments where they are often exposed. The present study aims to examine the effect of the 2015 SFOA amendment on rates of asthma and asthma-related health services use (HSU) in children with asthma. This study will contribute evidence on the effects of smoke-free legislation in children and on the effects of this type of smoke-free legislation targeted at reducing smoke exposure among children for the first time. This study will add to existing literature by examining the impact of smoke-free legislation in outdoor areas among children with asthma.

\section{METHODS}

\section{Study design and population}

We compiled a 9-year population-based open cohort study from January 2010 to December 2018 using health administrative data from the province of Ontario, Canada. Each year, all individuals aged $0-18$ years with physician diagnosed asthma and a valid Ontario residence postal code were included in the study. Individuals with a physician diagnosis of asthma were identified using a validated case definition of at least one hospitalisation for asthma or at least two outpatient visits in two consecutive years. This case definition was demonstrated to have $89.7 \%$ sensitivity and $70.6 \%$ specificity. ${ }^{14}$

\section{Data sources}

Ontario health administrative databases were used to study HSU over time. The National Ambulatory Care Reporting System captures ED visits, the Canadian Institute for Health Information Discharge Abstract Database captures hospital admissions, the Ontario Health Insurance Plan claims database captures outpatient physician office visits, the provincial Registered Persons Database (RPDB) captures sociodemographic information, and the Ontario Asthma Surveillance Information System captures individuals with asthma. The health administrative databases were linked using unique coded identifiers at ICES (formerly the Institute for Clinical Evaluative Sciences) in Toronto, Ontario.

\section{SFOA amendment}

In 2015, the SFOA was amended to prohibit smoking on patios, playgrounds and sports fields to target and protect children from the harmful effects of smoke exposure. ${ }^{13}$ The public was informed of the policy change via provincial and municipal bodies using a variety of strategies ranging from posted signage indicating where smoking is not permitted, news releases, ${ }^{15}$ announcements including those streamed live, ${ }^{16}$ presentations at public meetings and distribution of information including pamphlets, brochures or web content. ${ }^{17}$ Enforcement methods range from implementation of government regulations and inspections for compliance by inspectors or enforcement staff. ${ }^{17}$ Individuals who smoke where it is not allowed may be charged with an offence and fined (US\$1000 for a first offence, US $\$ 5000$ for any further offence) if convicted. ${ }^{13} 18$

Previously, the SFOA protected Ontarians from exposure to secondhand smoke in enclosed public places and enclosed workplaces since $2006,{ }^{19}$ as well as children under 16 years from such exposure in motor vehicles since $2009 .^{20}$ Changes around the SFOA since 2015 have focused on protecting youth from the health effects of electronic cigarettes or vaping, such as banning the sale and supply of electronic cigarettes to youth under 19 years, increasing fines for youth-related sales offences, and restricting the sales and promotion of vapour products in retail stores. ${ }^{21} 22$

\section{Statistical analysis}

Descriptively, annual rates of HSU (ED visits, hospitalisations and outpatient physician office visits) for asthma and asthma-related conditions (eg, bronchitis, allergic rhinitis, influenza and pneumonia) were calculated. HSU rates were calculated per 100 individuals. Rates were further stratified by age groups as infants (0-1 years), preschoolers (2-4 years), school-aged children (5-9 and 10-14 years) and adolescents (15-18 years). Additional stratifications included sex-based and census-based deprivation quintiles, a proxy measure for socioeconomic status.

We used an interrupted time-series analysis ${ }^{23-25}$ to estimate changes in HSU following the 2015 SFOA amendment. The interrupted time-series analysis controls for baseline level and trend when estimating expected changes in the outcomes of interest that may be attributable to the intervention. The mean monthly HSU rates for asthma and asthma-related conditions in the post2015 SFOA amendment period were calculated assuming rates without 2015 SFOA and compared with estimated rates with 2015 SFOA.

The characteristics of the study population were summarised based on January 2010, 2015 and 2018. The monthly ED visit, hospitalisation and physician office visit rates were calculated from January 2010 to December 2018 for asthma and asthma-related conditions. The 2015 SFOA amendment was effective in January 2015 (month 61 ). We used autoregressive models that included autoregressive terms to account for the autocorrelation and seasonality, at a given seasonal lag, in the interrupted time-series data. ${ }^{26}$ Autocorrelation can also be a consequence of seasonality. The autoregressive terms included adjusted for and balanced any seasonal or cyclical patterns between the preintervention and postintervention periods. The Durbin-Watson statistics were used to test for the presence of autocorrelation of order 12 or smaller. The autoregressive models were estimated using 
the maximum likelihood method. The autocorrelation functions and partial autocorrelation functions were examined in plotted graphs to ascertain that the correlation between any two data points fell within the acceptable range.

The intervention's effects may vary across different subpopulations of individuals. We conducted the interrupted time-series analysis stratifying for these covariates: age group, sex and deprivation quintiles. The absolute effect of the 2015 SFOA amendment was determined as the difference between the estimated HSU rates based on the 2015 SFOA and the calculated counterfactual values at 36 months post-2015 SFOA. The 95\% CIs of the absolute difference were calculated according to methods used previously by Zhang $e t a l .^{27}$ Additional detail on the calculations is provided in an online supplemental material 1. All statistical analyses were conducted using SAS V.9.4 (SAS Institute).

\section{Patient and public involvement}

It was not appropriate or possible to involve patients or the public in the design, or conduct, or reporting, or dissemination plans of our research.

\section{RESULTS}

\section{Population characteristics}

The study population consisted of Ontario residents 0-18 years of age with physician diagnosed asthma. The study population ranged from 618957 individuals in 2010 to 498812 in 2018 (table 1). Incidence of asthma among individuals $0-18$ years of age in Ontario decreased over the study period leading to lower asthma prevalence over time. ${ }^{28}$ The study population characteristics were similar throughout the 9 -year study period. The majority of the study population were male $(59.2 \%$ in 2010$)$ and the largest proportion were aged 10 to 14 years $(31.6 \%$ in 2010). In 2010, the average asthma duration was 8.83 years (SD: 5.19 years) and the average age at asthma diagnosis was 2.94 years (SD: 3.42 years). Most individuals lived in urban areas (90.6\% in 2010). The study population was evenly distributed across the five deprivation quintiles, with $18.4 \%$ residing in neighbourhoods in the lowest quintile and $22.4 \%$ residing in neighbourhoods in the highest quintile in 2010. A small portion of the study population (3.2\% in 2010) had immigrated to Canada.

\section{Results from interrupted time-series analysis \\ ED visit rates for asthma}

There were no statistically significant changes in the ED visit rates for asthma in the study population post-2015 SFOA except among infants (figure 1A and table 2A). In infants $0-1$ years of age, the interrupted time-series analysis showed a significant increase in ED visits for asthma corresponding to the January 2015 SFOA amendment. The estimated average increase in the ED visit rate for asthma in infants was 0.42 per 100 individuals $(95 \% \mathrm{CI}$ : 0.09 to 0.75 ) from 0.74 to 1.16 per 100 individuals, pre-2015 and post-2015 SFOA, respectively. This change implied an overall $57 \%$ relative increase in asthma ED visits among infants in the 36 months post-2015 SFOA. There were no significant differences observed when stratified by sex and deprivation quintile.

The interrupted time-series analysis showed a significant decrease in ED visits for asthma-related conditions (eg, bronchitis, allergic rhinitis, influenza and pneumonia) corresponding to the 2015 SFOA amendment (figure 1B and table 2B). The estimated average decrease in the $\mathrm{ED}$ visit rate for asthma-related conditions was 0.19 per 100 individuals (95\% CI: -0.37 to -0.01 ) from 0.85 to 0.66 per 100 individuals, pre-2015 and post-2015 SFOA, respectively. This change implied a $22 \%$ relative decrease in ED visits in the 36 months post-2015 SFOA. The change was more pronounced in infants aged $0-1$ years and preschoolers aged $2-4$ years $(16 \%$ and $18 \%$ relative decrease in ED visits for asthma-related conditions, respectively). The change was statistically significant in females and those in the highest deprivation quintile (16\% and 23\% relative decrease in ED visits for asthmarelated conditions, respectively).

\section{Hospital admissions for asthma and asthma-related conditions}

From the interrupted time-series analysis, there were no observed statistically significant changes in the hospital admission rates for asthma and asthma-related conditions in the overall study population post-2015 SFOA (figure 2A,B). However, the change in hospital admission for asthma-related conditions was statistically significant in preteens 10-14 years of age and those in the lowest deprivation quintile $(43 \%$ and $30 \%$ relative decrease in hospital admissions for asthma-related conditions, respectively, table 2B).

\section{Physician visits for asthma and asthma-related conditions}

From the interrupted time-series analysis, there were no statistically significant changes in the physician visit rates for asthma and asthma-related conditions observed in the overall study population post-2015 SFOA (figure 3A,B). However, the change in physician visits for asthmarelated conditions was statistically significant in infants $0-1$ years of age $(20 \%$ relative decrease in physician visits for asthma-related conditions, table 2B). There were no significant differences observed when stratified by sex and deprivation quintile.

\section{DISCUSSION}

A recent meta-analysis that included studies from North America and Europe found that smoke-free legislation resulted in an immediate and significant reduction of asthma exacerbation requiring hospital attendance. ${ }^{11}$ However, the extent of this difference, especially in children, remains poorly understood. Some studies found that smoke-free legislation led to reduced paediatric asthma-related HSU, ${ }^{8-10}$ while others found no effect. ${ }^{67}$ 
Table 1 Characteristics of the study population in 2010, 2015 and 2018

\begin{tabular}{|c|c|c|c|}
\hline \multirow[b]{4}{*}{ Characteristic } & \multicolumn{3}{|c|}{$\mathrm{N}$ or mean or median } \\
\hline & \multicolumn{3}{|l|}{ (\% or SD or IQR) } \\
\hline & 2010 & 2015 & 2018 \\
\hline & $(\mathrm{N}=618957)$ & $(\mathrm{N}=545950)$ & $(\mathrm{N}=498812)$ \\
\hline \multicolumn{4}{|l|}{ Sex } \\
\hline Male & $366361(59.2 \%)$ & $324160(59.4 \%)$ & $296176(59.4 \%)$ \\
\hline Female & $252596(40.8 \%)$ & $221790(40.6 \%)$ & $202636(40.6 \%)$ \\
\hline \multicolumn{4}{|c|}{ Age group at 1 January of each year (years) } \\
\hline $0-1$ & $25917(4.2 \%)$ & $20742(3.8 \%)$ & $15482(3.1 \%)$ \\
\hline $2-4$ & $64014(10.3 \%)$ & $56913(10.4 \%)$ & $49301(9.9 \%)$ \\
\hline $5-9$ & $151160(24.4 \%)$ & $137438(25.2 \%)$ & $126928(25.4 \%)$ \\
\hline $10-14$ & $195788(31.6 \%)$ & $169732(31.1 \%)$ & $158997(31.9 \%)$ \\
\hline $15-18$ & $182078(29.4 \%)$ & $161125(29.5 \%)$ & $148104(29.7 \%)$ \\
\hline \multicolumn{4}{|c|}{ Age at 1 January of each year (years) } \\
\hline Mean (SD) & $10.76(5.06)$ & $10.77(5.04)$ & $10.90(4.93)$ \\
\hline Median (IQR) & $11.00(7.00-15.00)$ & $11.00(7.00-15.00)$ & $11.00(7.00-15.00)$ \\
\hline \multicolumn{4}{|c|}{ Asthma duration (years) } \\
\hline Mean (SD) & $8.83(5.19)$ & $8.88(5.26)$ & $9.02(5.14)$ \\
\hline Median (IQR) & $8.79(4.39-13.07)$ & $8.77(4.35-13.13)$ & $8.85(4.63-13.18)$ \\
\hline \multicolumn{4}{|c|}{ Age at asthma diagnosis (years) } \\
\hline Mean (SD) & $2.94(3.42)$ & $2.90(3.30)$ & $2.90(3.22)$ \\
\hline Median (IQR) & $2.00(0.00-4.00)$ & $2.00(0.00-4.00)$ & $2.00(1.00-4.00)$ \\
\hline \multicolumn{4}{|l|}{ Rurality } \\
\hline Urban & $560617(90.6 \%)$ & $504340(92.4 \%)$ & $462566(92.7 \%)$ \\
\hline Rural & $58340(9.4 \%)$ & $41610(7.6 \%)$ & $36246(7.3 \%)$ \\
\hline \multicolumn{4}{|l|}{ Income quintile } \\
\hline 1 (lowest) & $113893(18.4 \%)$ & $100531(18.4 \%)$ & $88611(17.8 \%)$ \\
\hline 2 & $115325(18.6 \%)$ & $99354(18.2 \%)$ & $89570(18.0 \%)$ \\
\hline 3 & $128303(20.7 \%)$ & $111529(20.4 \%)$ & $102626(20.6 \%)$ \\
\hline 4 & $134809(21.8 \%)$ & $116679(21.4 \%)$ & $110133(22.1 \%)$ \\
\hline 5 (highest) & $124254(20.1 \%)$ & $117838(21.6 \%)$ & $107855(21.6 \%)$ \\
\hline Missing & $2373(0.4 \%)$ & $19(0.0 \%)$ & $17(0.0 \%)$ \\
\hline \multicolumn{4}{|c|}{ Deprivation quintile } \\
\hline 1 (lowest) & $114040(18.4 \%)$ & $119285(21.8 \%)$ & $115566(23.2 \%)$ \\
\hline 2 & $120281(19.4 \%)$ & $117801(21.6 \%)$ & $109217(21.9 \%)$ \\
\hline 3 & $119327(19.3 \%)$ & $103521(19.0 \%)$ & $93180(18.7 \%)$ \\
\hline 4 & $121905(19.7 \%)$ & $95335(17.5 \%)$ & $84258(16.9 \%)$ \\
\hline 5 (highest) & $138942(22.4 \%)$ & 106957 (19.6\%) & $93933(18.8 \%)$ \\
\hline Missing & $4462(0.7 \%)$ & $3051(0.6 \%)$ & $2658(0.5 \%)$ \\
\hline \multicolumn{4}{|c|}{ Dependency quintile } \\
\hline 1 (lowest) & $186472(30.1 \%)$ & 182695 (33.5\%) & $174585(35.0 \%)$ \\
\hline 2 & $138116(22.3 \%)$ & $119893(22.0 \%)$ & $108006(21.7 \%)$ \\
\hline 3 & $112463(18.2 \%)$ & 92291 (16.9\%) & $81818(16.4 \%)$ \\
\hline 4 & $96476(15.6 \%)$ & 80799 (14.8\%) & 72219 (14.5\%) \\
\hline 5 (highest) & $80968(13.1 \%)$ & $67221(12.3 \%)$ & $59526(11.9 \%)$ \\
\hline Missing & $4462(0.7 \%)$ & $3051(0.6 \%)$ & $2658(0.5 \%)$ \\
\hline
\end{tabular}




\begin{tabular}{|c|c|c|c|}
\hline \multirow[b]{4}{*}{ Characteristic } & \multicolumn{3}{|c|}{$\mathbf{N}$ or mean or median } \\
\hline & \multicolumn{3}{|l|}{ (\% or SD or IQR) } \\
\hline & 2010 & 2015 & 2018 \\
\hline & $(\mathrm{N}=618957)$ & $(\mathrm{N}=545950)$ & $(\mathrm{N}=498812)$ \\
\hline \multicolumn{4}{|c|}{ Ethnic concentration quintile } \\
\hline 1 (lowest) & $83917(13.6 \%)$ & $61236(11.2 \%)$ & 52892 (10.6\%) \\
\hline 2 & 93010 (15.0\%) & 75770 (13.9\%) & 66684 (13.4\%) \\
\hline 3 & $115791(18.7 \%)$ & $91276(16.7 \%)$ & 82955 (16.6\%) \\
\hline 4 & $130987(21.2 \%)$ & $120077(22.0 \%)$ & $111120(22.3 \%)$ \\
\hline 5 (highest) & $190790(30.8 \%)$ & $194540(35.6 \%)$ & $182503(36.6 \%)$ \\
\hline Missing & $4462(0.7 \%)$ & $3051(0.6 \%)$ & $2658(0.5 \%)$ \\
\hline \multicolumn{4}{|c|}{ Residential instability quintile } \\
\hline 1 (lowest) & $187436(30.3 \%)$ & $163605(30.0 \%)$ & $149482(30.0 \%)$ \\
\hline 2 & $128766(20.8 \%)$ & $108868(19.9 \%)$ & $100204(20.1 \%)$ \\
\hline 3 & $110165(17.8 \%)$ & $92641(17.0 \%)$ & $85906(17.2 \%)$ \\
\hline 4 & $105809(17.1 \%)$ & $91223(16.7 \%)$ & $81809(16.4 \%)$ \\
\hline 5 (highest) & $82319(13.3 \%)$ & $86562(15.9 \%)$ & $78753(15.8 \%)$ \\
\hline Missing & $4462(0.7 \%)$ & $3051(0.6 \%)$ & $2658(0.5 \%)$ \\
\hline \multicolumn{4}{|l|}{ Immigration } \\
\hline Yes & $19895(3.2 \%)$ & $18649(3.4 \%)$ & 16301 (3.3\%) \\
\hline \multicolumn{4}{|l|}{ Death count } \\
\hline Yes & $123(0.0 \%)$ & 105 (0.0\%) & $113(0.0 \%)$ \\
\hline
\end{tabular}

Asthma prevalence aged 0-18 on 1 January in 2010, 2015 and 2018 were included, respectively.

People with missing health region and rurality were excluded.

$I Q R$, Interquartile range

; SD, Standard deviation

Using 9 years of health administrative data from Ontario, Canada, our study was one of the largest population-based studies to examine the impact of smoke-free legislation in children to date.

This study examined the effect of the 2015 SFOA amendment, which prohibited smoking on patios, playgrounds and sports fields, on HSU rates in children with asthma. ${ }^{13}$ A survey conducted by the Ontario Tobacco Research Unit found significantly decreased self-reported smoking and self-reported secondhand smoking exposure at playgrounds, sports fields, restaurants and park festivals between 2014 and $2015 .^{29}{ }^{30}$ In the first year after the 2015 SFOA amendment was implemented, compliance with smoking regulations was $96 \%$ for patios, $89 \%$ for playgrounds and $86 \%$ for sporting areas. ${ }^{30}$ In 2016 , compliance with smoking regulations fell to $93 \%$ for patios, $73 \%$ for playgrounds and $72 \%$ for sporting areas. ${ }^{30}$ Through efforts like the Smoke-Free Ontario Strategy, the smoking rate in Ontario decreased from 20.9\% in 2005 to $17.4 \%$ in $2014 .^{31}$

Similar to an older study that used health administrative data from Prince Edward Island in Canada, our study also did not find a significant difference post smoke-free legislation in the asthma-specific hospital admission rate in children with asthma. ${ }^{7}$ Rather, we found a small increase in ED visits for asthma post-2015 SFOA amendment in infants $0-1$ years of age. While this difference is statistically significant, the absolute difference is relatively small. Asthma-specific HSU rates are affected by many factors, and it is unclear what may be the contributing factor for this observed difference. A possible explanation may be confounding by indication where (1) infants $0-1$ years of age likely do not spend enough time outdoors in playgrounds and parks to benefit from a smoke-free environment and/or (2) young children being diagnosed by physicians as having asthma tend to have few day-to-day symptoms but are prone to exacerbations, ${ }^{32}{ }^{33}$ so their risk of having an exacerbation requiring a visit to the ED may not be modified by smoke-free legislation alone.

In this study, we found a statistically significant decrease in ED visits for asthma-related conditions (eg, bronchitis, allergic rhinitis, influenza and pneumonia) corresponding to the 2015 SFOA amendment. Similarly, in a recent meta-analysis, the authors found that the implementation of smoke-free legislation was associated with reductions in rates of hospital attendance for 

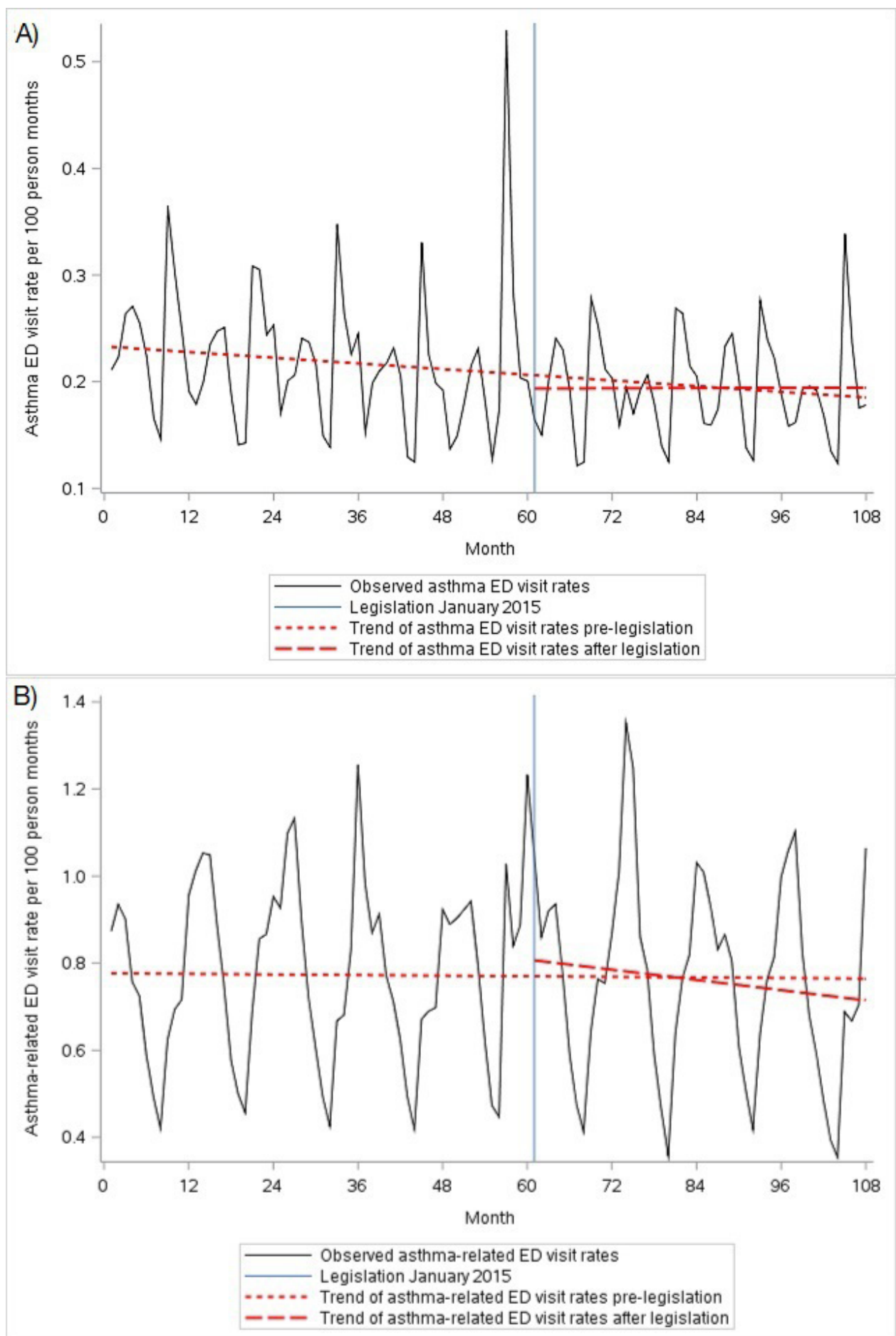

Figure 1 Time series graphs for emergency department (ED) visit rates. (A) Asthma ED visit rate overall. (B) Asthma-related ED visit rate overall.

all respiratory tract infections and for lower respiratory tract infections. ${ }^{11}$ Our data also showed a significant decrease in asthma-related ED observed in children of lower income families. Compared with children residing in lower deprivation neighbourhoods who may have superior access to private play spaces, children in neighbourhoods with higher deprivation may spend more time in public playgrounds. ${ }^{3435}$ This may explain the decrease in their asthma-related ED visits before and after the 2015
SFOA amendment. The change may also be attributable to higher baseline exposure to tobacco smoke among children living in lower deprivation neighbourhoods. ${ }^{36} 37$

\section{Strengths and limitations}

This population-based study has several strengths. The use of health administrative data allowed us to collect information about HSU for asthma and asthma-related conditions among all Ontario residents $0-18$ years of age 
Table 2 Estimation of the absolute effect of 2015 SFOA amendment

\begin{tabular}{|c|c|c|c|c|c|}
\hline \multirow{2}{*}{ Outcome } & & \multicolumn{2}{|c|}{ Mean monthly rate } & \multirow[b]{2}{*}{ Mean monthly change $(95 \% \mathrm{Cl})$} & \multirow[t]{2}{*}{ Relative \% change } \\
\hline & & Without SFOA & With SFOA & & \\
\hline \multicolumn{6}{|c|}{ (A) Effect on health services use for asthma } \\
\hline \multicolumn{6}{|c|}{ Asthma ED visit rate per 100 individuals } \\
\hline Overall & & 0.212 & 0.203 & $-0.010(-0.0766$ to 0.0576$)$ & -4.48 \\
\hline \multirow[t]{5}{*}{ Age } & $0-1$ & 0.738 & 1.158 & $0.420(0.0941 \text { to } 0.7453)^{*}$ & 56.86 \\
\hline & $2-4$ & 0.581 & 0.582 & $0.001(-0.2100$ to 0.2121$)$ & 0.18 \\
\hline & $5-9$ & 0.241 & 0.216 & $-0.025(-0.0677$ to 0.0181$)$ & -10.30 \\
\hline & $10-14$ & 0.119 & 0.108 & $-0.011(-0.0411$ to 0.0192$)$ & -9.22 \\
\hline & $15-18$ & 0.100 & 0.095 & $-0.006(-0.0359$ to 0.0243$)$ & -5.75 \\
\hline \multirow[t]{2}{*}{ Sex } & Male & 0.224 & 0.212 & $-0.012(-0.0865$ to 0.0633$)$ & -5.19 \\
\hline & Female & 0.198 & 0.188 & $-0.010(-0.0595$ to 0.0402$)$ & -4.88 \\
\hline \multirow[t]{5}{*}{ Deprivation } & Q1 (least) & 0.172 & 0.171 & $-0.001(-0.0497$ to 0.0487$)$ & -0.29 \\
\hline & Q2 & 0.183 & 0.178 & $-0.006(-0.0574$ to 0.0464$)$ & -3.00 \\
\hline & Q3 & 0.207 & 0.189 & $0.000(-0.0781$ to 0.0407$)$ & 0.00 \\
\hline & Q4 & 0.225 & 0.215 & $-0.010(-0.0941$ to 0.0740$)$ & -4.48 \\
\hline & Q5 (most) & 0.283 & 0.247 & $-0.036(-0.1124$ to 0.0397$)$ & -12.83 \\
\hline
\end{tabular}

Asthma hospital admission rate per 100 individuals

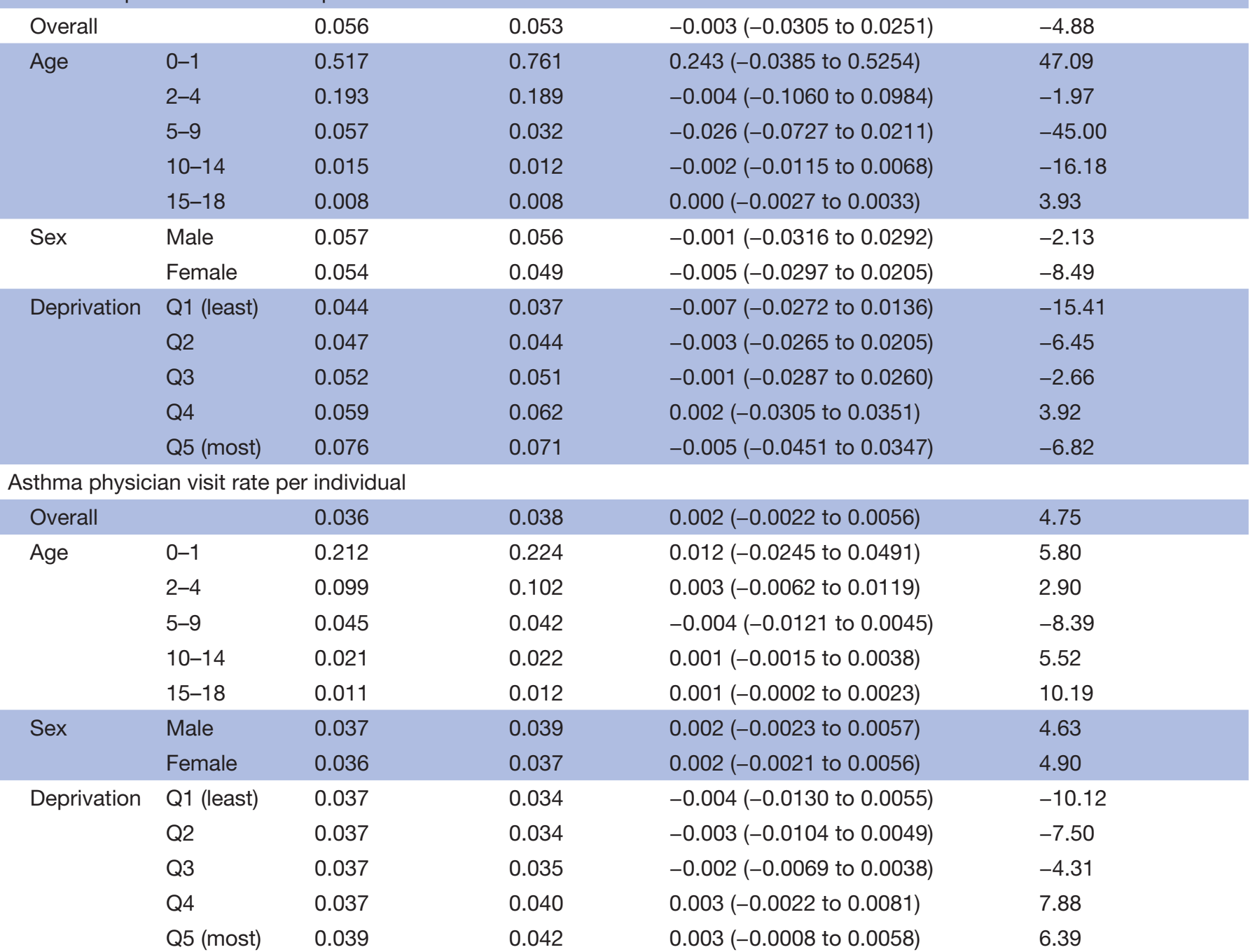

(B) Effect on health services use for asthma-related conditions 
Table 2 Continued

\begin{tabular}{|c|c|c|c|c|c|}
\hline \multirow[b]{2}{*}{ Outcome } & & \multicolumn{2}{|c|}{ Mean monthly rate } & \multirow[b]{2}{*}{ Mean monthly change $(95 \% \mathrm{Cl})$} & \multirow[t]{2}{*}{ Relative $\%$ change } \\
\hline & & Without SFOA & With SFOA & & \\
\hline \multicolumn{6}{|c|}{ Asthma-related ED visit rate per 100 individuals } \\
\hline Overall & & 0.854 & 0.664 & $-0.190(-0.3722 \text { to }-0.0075)^{\star}$ & -22.23 \\
\hline \multirow[t]{5}{*}{ Age } & $0-1$ & 6.872 & 5.781 & $-1.091(-2.0908 \text { to }-0.0908)^{\star}$ & -15.87 \\
\hline & $2-4$ & 2.213 & 1.821 & $-0.392(-0.7775 \text { to }-0.0063)^{\star}$ & -17.71 \\
\hline & $5-9$ & 0.677 & 0.595 & $-0.082(-0.2008$ to 0.0366$)$ & -12.13 \\
\hline & $10-14$ & 0.352 & 0.317 & $-0.035(-0.1270$ to 0.0571$)$ & -9.92 \\
\hline & $15-18$ & 0.435 & 0.369 & $-0.066(-0.2024$ to 0.0710$)$ & -15.12 \\
\hline \multirow[t]{2}{*}{ Sex } & Male & 0.792 & 0.704 & $-0.088(-0.1980$ to 0.0222$)$ & -11.10 \\
\hline & Female & 0.843 & 0.709 & $-0.133(-0.2506 \text { to }-0.0159)^{*}$ & -15.81 \\
\hline \multirow[t]{5}{*}{ Deprivation } & Q1 (least) & 0.632 & 0.588 & $-0.044(-0.1321$ to 0.0439$)$ & -6.97 \\
\hline & Q2 & 0.762 & 0.599 & $-0.163(-0.3466$ to 0.0198$)$ & -21.43 \\
\hline & Q3 & 0.809 & 0.702 & $0.000(-0.2164$ to 0.0031$)$ & 0.00 \\
\hline & Q4 & 0.898 & 0.747 & $-0.152(-0.3439$ to 0.0405$)$ & -16.89 \\
\hline & Q5 (most) & 1.041 & 0.804 & $-0.237(-0.4514 \text { to }-0.0226)^{\star}$ & -22.78 \\
\hline \multicolumn{6}{|c|}{ Asthma-related hospital admission rate per 100 individuals } \\
\hline Overall & & 0.090 & 0.073 & $-0.016(-0.0388$ to 0.0059$)$ & -18.40 \\
\hline \multirow[t]{5}{*}{ Age } & $0-1$ & 1.642 & 1.479 & $-0.163(-0.9228$ to 0.5254$)$ & -9.92 \\
\hline & $2-4$ & 0.220 & 0.174 & $-0.046(-0.0966$ to 0.0037$)$ & -21.10 \\
\hline & $5-9$ & 0.049 & 0.041 & $-0.008(-0.0290$ to 0.0128$)$ & -16.45 \\
\hline & $10-14$ & 0.022 & 0.013 & $-0.009(-0.0183 \text { to }-0.0006)^{\star}$ & -42.62 \\
\hline & $15-18$ & 0.016 & 0.014 & $-0.002(-0.0066$ to 0.0023$)$ & -13.63 \\
\hline \multirow[t]{2}{*}{ Sex } & Male & 0.090 & 0.075 & $-0.015(-0.0380$ to 0.0079$)$ & -16.76 \\
\hline & Female & 0.090 & 0.071 & $-0.019(-0.0425$ to 0.0043$)$ & -21.31 \\
\hline \multirow[t]{5}{*}{ Deprivation } & Q1 (least) & 0.076 & 0.053 & $-0.023(-0.0457 \text { to }-0.0006)^{\star}$ & -30.39 \\
\hline & Q2 & 0.076 & 0.062 & $-0.013(-0.0306$ to 0.0044$)$ & -17.32 \\
\hline & Q3 & 0.089 & 0.068 & $-0.021(-0.0440$ to 0.0022$)$ & -23.57 \\
\hline & Q4 & 0.091 & 0.083 & $-0.009(-0.0275$ to 0.0103$)$ & -9.42 \\
\hline & Q5 (most) & 0.112 & 0.100 & $-0.012(-0.0437$ to 0.0194$)$ & -10.87 \\
\hline \multicolumn{6}{|c|}{ Asthma-related physician visit rate per individual } \\
\hline Overall & & 0.093 & 0.090 & $-0.002(-0.0120$ to 0.0072$)$ & -2.59 \\
\hline \multirow[t]{5}{*}{ Age } & $0-1$ & 0.395 & 0.315 & $-0.081(-0.1561 \text { to }-0.0053)^{*}$ & -20.40 \\
\hline & $2-4$ & 0.185 & 0.177 & $-0.008(-0.0260$ to 0.0095$)$ & -4.48 \\
\hline & $5-9$ & 0.105 & 0.098 & $0.107(-0.0200$ to 0.0063$)$ & 101.55 \\
\hline & $10-14$ & 0.066 & 0.067 & $-0.007(-0.0098$ to 0.0104$)$ & -10.34 \\
\hline & $15-18$ & 0.056 & 0.058 & $0.001(-0.0067$ to 0.0096$)$ & 2.58 \\
\hline \multirow[t]{2}{*}{ Sex } & Male & 0.089 & 0.087 & $-0.002(-0.0116$ to 0.0068$)$ & -2.69 \\
\hline & Female & 0.098 & 0.096 & $-0.002(-0.0129$ to 0.0079$)$ & -2.54 \\
\hline \multirow[t]{5}{*}{ Deprivation } & Q1 (least) & 0.087 & 0.077 & $-0.009(-0.0245$ to 0.0060$)$ & -10.65 \\
\hline & Q2 & 0.091 & 0.084 & $-0.007(-0.0183$ to 0.0045$)$ & -7.64 \\
\hline & Q3 & 0.094 & 0.089 & $-0.006(-0.0157$ to 0.0044$)$ & -6.01 \\
\hline & Q4 & 0.099 & 0.099 & $0.000(-0.0104$ to 0.0110$)$ & 0.26 \\
\hline & Q5 (most) & 0.099 & 0.100 & $0.001(-0.0097$ to 0.0113$)$ & 0.81 \\
\hline
\end{tabular}

Continued 
Table 2 Continued

\begin{tabular}{|c|c|c|c|c|}
\hline & Mean monthly & & & Relative \% change \\
\hline Outcome & Without SFOA & With SFOA & Mean monthly change $(95 \% \mathrm{Cl})$ & \\
\hline
\end{tabular}

ED visit rates for asthma-related conditions.

*Indicates statistical significance.

ED, emergency department; SFOA, smoke-free Ontario act.
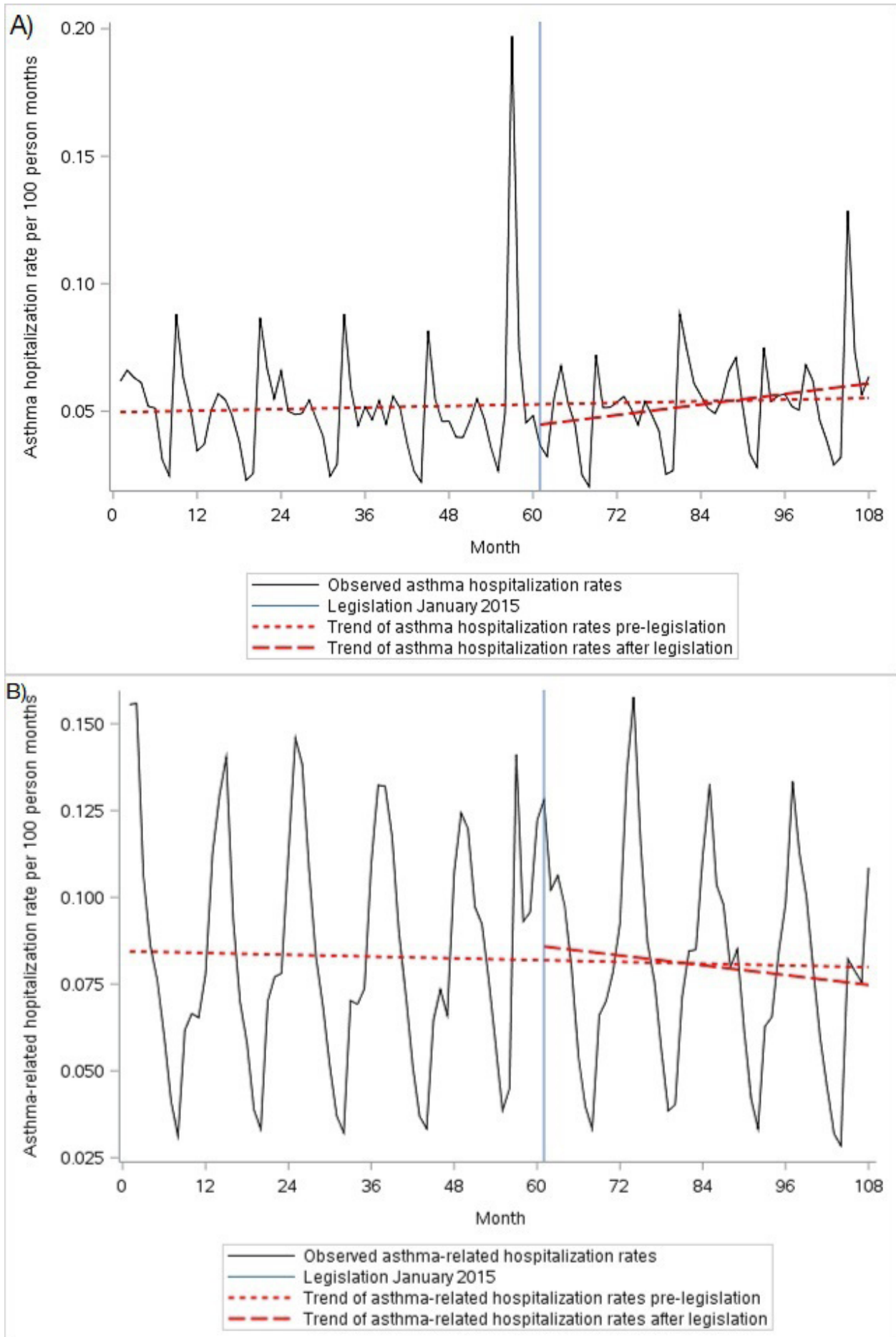

Figure 2 Time series graphs for hospitalisation rates. (A) Asthma hospitalisation rate overall. (B) Asthma-related hospitalisation rate overall. 

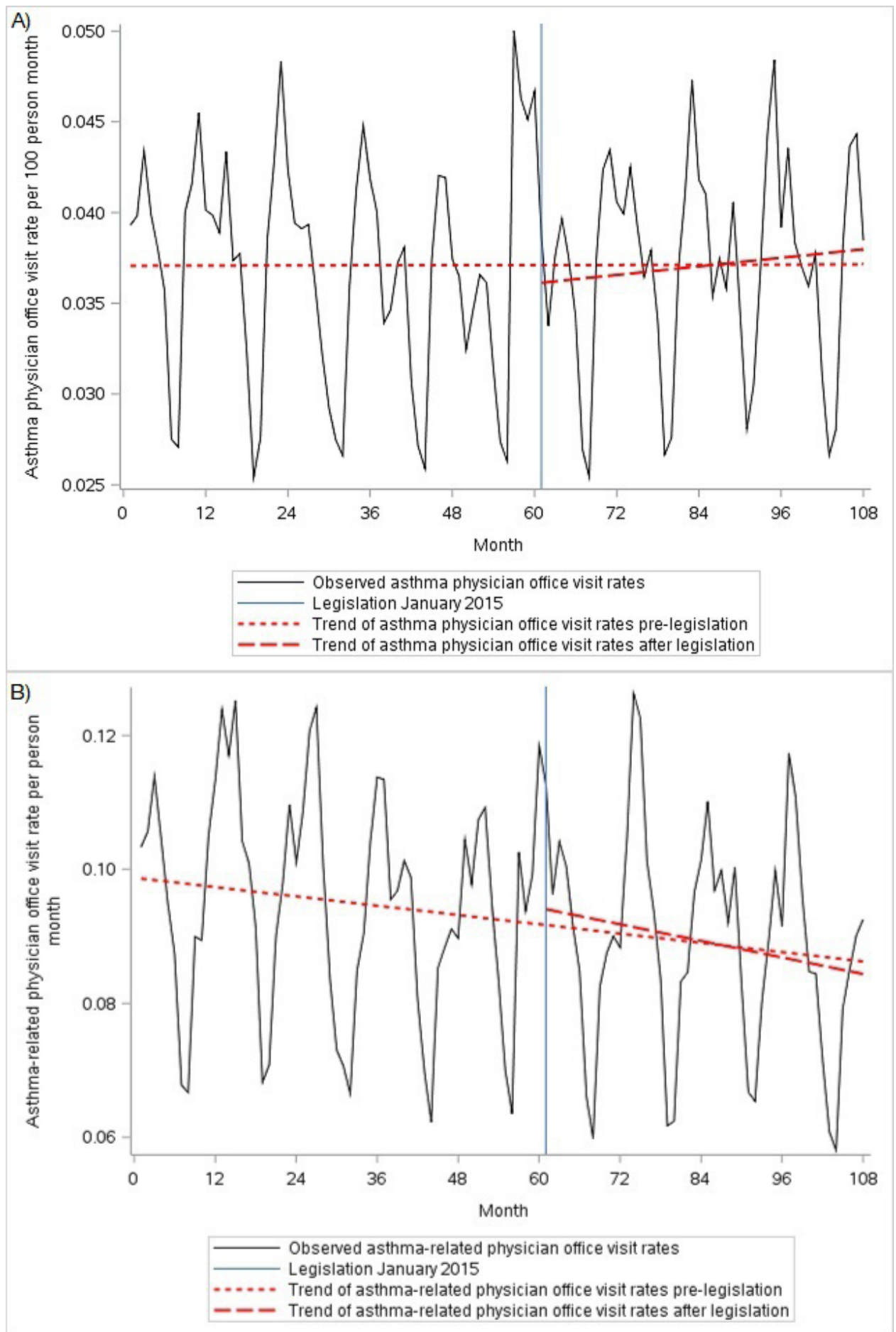

Figure 3 Time series graphs for physician office visit rates. (A) Asthma physician office visit rate overall. (B) Asthma-related physician office visit rate overall.

with asthma over a 9-year period. This data source allowed us to study HSU without selection or response bias, and may allow us to generalise our results to other populations in other regions. There are also some limitations to our study. The use of health administrative data limited our ability to examine clinically relevant risk factors such as asthma severity, medication use, comorbid conditions, parental smoking and unplanned versus planned healthcare visits. Our ability to account for reduction in air pollution and smoking in the population due to other campaigns was also limited. We did not include a control province as smoke-free legislation varies across Canada and identifying a province where such legislation has not been implemented is not straightforward. Furthermore, since the interrupted time-series analysis was used to calculate mean monthly HSU rates on an ecological level, we were limited in our ability to infer the impact of the intervention on an individual level. 


\section{CONCLUSION}

This population-based study used 9years of health administrative data to study the impact of the 2015 SFOA amendment on respiratory HSU in children with asthma. We found that while the 2015 SFOA amendment did not impact healthcare use for asthma specifically, it had a greater and significant impact on healthcare use for asthma-related conditions (eg, bronchitis, allergic rhinitis, influenza and pneumonia) in children living with asthma. Based on the positive effect of restricting smoking on patios, playgrounds, and sports fields on respiratory morbidity in children with asthma observed in this study, other jurisdictions globally should consider implementing similar smoke-free policies. Additionally, Ontario should improve compliance with this smoke-free policy by continuing to educate the public on the harmful effects of smoking, especially on children.

Acknowledgements Data were provided by ICES, which is funded by an annual grant from the Ontario Ministry of Health and Long-Term Care. Parts of this material are based on data and information compiled and provided by the Canadian Institute for Health Information.

Contributors TT initiated and designed the study, interpreted findings and drafted the manuscript. IF drafted the manuscript, summarised findings and composed tables and figures. JZ conducted all statistical analysis and drafted the manuscript. RM initiated the study and drafted and reviewed the manuscript. KZ and ET conducted a search of the literature, summarised relevant study findings and reviewed the manuscript. All authors approved the final manuscript as submitted and agreed to be accountable for all aspects of the work.

Funding This work was supported by the Ontario Ministry of Health and Long-Term Care, grant number HLTC3968IT-2019. Dr. Teresa To holds a Canadian Institutes of Health Research Tier 1 Canada Research Chair in Asthma, grant number CRC-508110. The funders had no role in study design; in the collection, analysis, and interpretation of data; in the writing of the manuscript; and in the decision to submit the manuscript for publication.

Disclaimer The analyses, conclusions, opinions, and statements expressed herein are those of the authors and do not necessarily reflect those of the data sources; no endorsement is intended or should be inferred.

Competing interests None declared.

Patient consent for publication Not required.

Ethics approval Ethics approval exemption was obtained from the Hospital for Sick Children Research Ethics Board. Ethics approval was exempted because this study uses only health administrative data housed at ICES under the Personal Health Information Protection Act (PHIPA) section 45, for the purpose of analysis or compiling statistical information with respect to the management of, evaluation or monitoring of, the allocation of resources to or planning for all or part of the health system, including the delivery of services, as determined by ICES Privacy Impact Assessment review. Individual consent was not required as only deidentified provincial health administrative data were used in this study.

Provenance and peer review Not commissioned; externally peer reviewed.

Data availability statement Data may be obtained from a third party and are not publicly available. No additional data available.

Supplemental material This content has been supplied by the author(s). It has not been vetted by BMJ Publishing Group Limited (BMJ) and may not have been peer-reviewed. Any opinions or recommendations discussed are solely those of the author(s) and are not endorsed by BMJ. BMJ disclaims all liability and responsibility arising from any reliance placed on the content. Where the content includes any translated material, BMJ does not warrant the accuracy and reliability of the translations (including but not limited to local regulations, clinical guidelines, terminology, drug names and drug dosages), and is not responsible for any error and/or omissions arising from translation and adaptation or otherwise.

Open access This is an open access article distributed in accordance with the Creative Commons Attribution Non Commercial (CC BY-NC 4.0) license, which permits others to distribute, remix, adapt, build upon this work non-commercially, and license their derivative works on different terms, provided the original work is properly cited, appropriate credit is given, any changes made indicated, and the use is non-commercial. See: http://creativecommons.org/licenses/by-nc/4.0/.

ORCID iD

Teresa To http://orcid.org/0000-0001-7463-3423

\section{REFERENCES}

1 Gergen PJ. Environmental tobacco smoke as a risk factor for respiratory disease in children. Respir Physiol 2001;128:39-46.

2 Etzel RA. How environmental exposures influence the development and exacerbation of asthma. Pediatrics 2003;112:233.

3 Ward M, Currie LM, Kabir Z, et al. The efficacy of different models of smoke-free laws in reducing exposure to second-hand smoke: a multi-country comparison. Health Policy 2013;110:207-13.

4 Semple S, Maccalman L, Naji AA, et al. Bar workers' exposure to second-hand smoke: the effect of Scottish smoke-free legislation on occupational exposure. Ann Occup Hyg 2007;51:571-80.

5 Fernando D, Fowles J, Woodward A, et al. Legislation reduces exposure to second-hand tobacco smoke in New Zealand bars by about 90\%. Tob Control 2007;16:235-8.

6 Galán I, Simón L, Boldo E, et al. Changes in hospitalizations for chronic respiratory diseases after two successive smoking bans in Spain. PLoS One 2017;12:e0177979.

7 Gaudreau K, Sanford CJ, Cheverie C, et al. The effect of a smoking ban on hospitalization rates for cardiovascular and respiratory conditions in Prince Edward Island, Canada. PLoS One 2013;8:e56102.

8 Hawkins SS, Hristakeva S, Gottlieb M, et al. Reduction in emergency department visits for children's asthma, ear infections, and respiratory infections after the introduction of state smoke-free legislation. Prev Med 2016;89:278-85.

9 Mackay D, Haw S, Ayres JG, et al. Smoke-Free legislation and hospitalizations for childhood asthma. N Engl J Med 2010;363:1139-45.

10 Millett C, Lee JT, Laverty AA, et al. Hospital admissions for childhood asthma after smoke-free legislation in England. Pediatrics 2013;131:e495-501.

11 Faber T, Kumar A, Mackenbach JP, et al. Effect of tobacco control policies on perinatal and child health: a systematic review and metaanalysis. Lancet Public Health 2017;2:e420-37.

12 Frazer K, Callinan JE, McHugh J, et al. Legislative smoking bans for reducing harms from secondhand smoke exposure, smoking prevalence and tobacco consumption. Cochrane Database Syst Rev 2016;2:CD005992.

13 Government of Ontario. Smoke-Free Ontario act, 2013. Available: https://www.ontariocanada.com/registry/view.do?postingld $=14482 \&$ language=en\#: :text=On\%20November\%2018\%2C\%202013\% 2C\%20the,Free\%20Ontario\%20Act\%20(SFOA).\&text=Prohibit\% 20smoking\%20of\%20tobacco\%20and\%20holding\%20of\% 20lighted\%20tobacco\%20on\%20playgrounds

14 To T, Dell S, Dick PT, et al. Case verification of children with asthma in Ontario. Pediatr Allergy Immunol 2006;17:69-76.

15 Ontario Ministry of Health and Long-Term Care. Smoking to be prohibited on patios, sport fields and playgrounds: Ontario further protecting children and youth from smoking, 2014. Available: https:// news.ontario.ca/en/release/30916/smoking-to-be-prohibited-onpatios-sport-fields-and-playgrounds

16 Ontario Ministry of Health and Long-Term Care. Protecting children and youth from smoking, 2014. Available: https://news.ontario.ca/en/ advisory/30909/protecting-children-and-youth-from-smoking

17 Kennedy RD, Zummach D, Filsinger S, et al. Reported municipal costs from outdoor smoke-free by-laws-experience from Ontario, Canada. Tob Induc Dis 2014;12:4.

18 Ontario Ministry of the Attorney General. Cannabis statute law amendment act, 2018, 2018. Available: https://news.ontario.ca/en/ backgrounder/50104/cannabis-statute-law-amendment-act-2018

19 Ontario Ministry of Health and Long-Term Care. A decade of progress toward a smoke-free Ontario: helping Ontarians lead healthier, more active lives, 2015. Available: https://news.ontario. ca/en/release/31547/a-decade-of-progress-toward-a-smoke-freeontario

20 Ontario Ministry of Health and Long-Term Care. Building on the smoke-free Ontario strategy, 2015. Available: https://news.ontario. ca/en/backgrounder/32898/building-on-the-smoke-free-ontariostrategy 
21 Ontario Ministry of Health and Long-Term Care. Statement by associate Minister of health and long-term care on new laws for electronic cigarettes and tobacco, 2015. Available: https://news. ontario.ca/en/statement/35400/statement-by-associate-minister-ofhealth-and-long-term-care-on-new-laws-for-electronic-cigarettes-a

22 Ontario Ministry of Health and Long-Term Care. Protecting youth from the dangers of vaping: Ontario banning the promotion of vaping products outside of specialty stores, 2019. Available: https://news. ontario.ca/en/release/54321/protecting-youth-from-the-dangers-ofvaping

23 Wagner AK, Soumerai SB, Zhang F, et al. Segmented regression analysis of interrupted time series studies in medication use research. J Clin Pharm Ther 2002;27:299-309.

24 Gunnell D, Hawton K, Bennewith O, et al. A multicentre programme of clinical and public health research in support of the National suicide prevention strategy for England. NIHR Journals Library 2013;1:1-216.

25 Ramsay CR, Matowe L, Grilli R, et al. Interrupted time series designs in health technology assessment: lessons from two systematic reviews of behavior change strategies. Int J Technol Assess Health Care 2003;19:613-23.

26 Bernal JL, Cummins S, Gasparrini A. Interrupted time series regression for the evaluation of public health interventions: a tutorial. Int J Epidemiol 2017;46:348-55

27 Zhang F, Wagner AK, Soumerai SB, et al. Methods for estimating confidence intervals in interrupted time series analyses of health interventions. J Clin Epidemiol 2009;62:143-8.

28 Ontario Asthma Surveillance Information System. Asthma surveillance: tables and graphs, 2020. Available: https://lab.research sickkids.ca/oasis/data-tables/
29 Jolene Dubray AM, Schwartz R. Evaluation of the smoke-free Ontario act outdoor smoking regulations. Ontario: Ontario Tobacco Research Unit, 2013.

30 Dubray J, Borland T, Chaiton M, et al. Evaluation of the smoke-free Ontario act outdoor smoking regulations. Ontario: Ontario Tobacco Research Unit, 2017.

31 Ontario Ministry of Health and Long-Term Care. Statement by the Minister of Health and long-term care on the auditor general's reports, 2017. Available: https://news.ontario.ca/en/statement/ 47365/statement-by-the-minister-of-health-and-long-term-care-onthe-auditor-generals-reports

32 Bacharier LB, Guilbert TW. Diagnosis and management of early asthma in preschool-aged children. J Allergy Clin Immunol 2012;130:287-96.

33 Trivedi M, Denton E. Asthma in children and Adults-What are the differences and what can they tell us about asthma? Front Pediatr 2019;7:256

34 Aarts M-J, Wendel-Vos W, van Oers HAM, et al. Environmental determinants of outdoor play in children: a large-scale crosssectional study. Am J Prev Med 2010;39:212-9.

35 Silver D, Giorgio M, Mijanovich T. Utilization patterns and perceptions of playground users in New York City. J Community Health 2014;39:363-71.

36 Singh GK, Siahpush M, Kogan MD. Disparities in children's exposure to environmental tobacco smoke in the United States, 2007. Pediatrics 2010;126:4-13.

37 Kit BK, Simon AE, Brody DJ, et al. Us prevalence and trends in tobacco smoke exposure among children and adolescents with asthma. Pediatrics 2013;131:407-14 